\title{
PENGARUH BRAND IMAGE TERHADAP LOYALITAS PELANGGAN DI TOKO OLEH-OLEH MALANG STRUDEL
}

\author{
Reza Palevi ${ }^{1}$, Luh Gede Leli Kusuma Dewi ${ }^{2}$, Putu Agus Wikanatha Sagita ${ }^{3}$ \\ ${ }^{1}$ Email: Rpalevi.rp@gmail.com \\ Program Studi S1 Industri Perjalanan Wisata, Fakultas Pariwisata, Universitas Udayana \\ ${ }^{2}$ Email: leli.kusumadewi@gmail.com \\ Program Studi S1 Industri Perjalanan Wisata, Fakultas Pariwisata, Universitas Udayana \\ ${ }^{3}$ Email: wika.fpar@gmail.com
}

\begin{abstract}
This study aims to determine the effect of brand image to customer loyalty in Malang Strudel Souvenir Store. The rapid development of Malang Strudel is the foundation of this research. In this study, the customer is tourist who visiting Malang and shopping for souvenirs at Malang Strudel Souvenir Store. This research uses quantitative descriptive data analysis technique using SPSS ver. 20 for Windows. Data were collected by distributing questionnaires to 166 respondents. This research is quantitative research using reliability test method, validity test, classic assumption test, correlation analysis, coefficient determination test, multiple linear regression analysis, $\mathrm{t}$ test, and $\mathrm{f}$ test. The variables used in this research are the strength of brand association (X1), uniqueness of brand association (X2), brand association advantage (X3) as independent variable and Customer Loyalty $(\mathrm{Y})$ as dependent variable. The result of this research is strength of brand association (X1) and favorability of brand association (X3) have positive and significant influence, while uniqueness of brand association (X2) has positive and insignificant effect. Simultaneously, strength of brand association (X1), uniqueness of brand association (X2), and favorability of brand association (X3) that make up the brand image, have an impact on customer loyalty. A total of $54.1 \%$ of customer loyalty can be explained by variable strength, uniqueness, and favorability. While the rest of $45.9 \%$ customer loyalty can be explained by other variables that have not been studied in this research.
\end{abstract}

\begin{abstract}
Abstrak: Penelitian ini bertujuan untuk mengetahui pengaruh brand image terhadap loyalitas pelanggan di toko oleh-oleh Malang Strudel. Perkembangan pesat dari toko oleh-oleh Malang Strudel inilah yang mendasari penelitian ini. Dalam penelitian ini, yang dimaksud pelanggan adalah wisatawan yang berkunjung ke Kota Malang dan berbelanja oleh-oleh di Toko Malang Strudel. Penelitian ini menggunakan teknik analisis data deskriptif kuantitatif dengan menggunakan SPSS ver. 20 for Windows. Data diambil dengan cara menyebarkan kuesioner kepada 166 responden. Penelitian ini adalah penelitian kuantitatif dengan menggunakan metode uji reliabilitas, uji validitas, uji asumsi klasik, analisis korelasi, uji koefisien determinasi, analisis regresi linear berganda, uji t, dan uji $\mathrm{f}$. Variabel yang digunakan dalam penelitian ini adalah kekuatan asosiasi merek (X1), keunikan asosiasi merek (X2), keuntungan asosiasi merek (X3) sebagai variabel bebas dan Loyalitas Pelanggan (Y) sebagai variabel terikat.Hasil dari penelitian ini kekuatan asosiasi merek (X1) dan keuntungan asosiasi merek (X3) berpengaruh positif dan signifikan, sedangkan variabel keunikan asosiasi merek (X2) berpengaruh postitif dan tidak signifikan. Secara simultan, variabel kekuatan asosiasi merek (X1), keunikan asosiasi merek (X2), keuntungan asosiasi merek (X3) yang membentuk brand image, berpengaruh terhadap loyalitas pelanggan. Sebanyak 54,1\% loyalitas pelanggan dapat dijelaskan oleh variabel kekuatan asosiasi merek, keunikan asosiasi merek, dan keuntungan asosiasi merek. Sedangkan sisanya yaitu 45,9\% loyalitas pelanggan dapat dijelaskan oleh variabel lain yang belum diteliti dalam penelitian ini.
\end{abstract}

Keywords: brand image, customer loyalty, malang strudel. 


\section{PENDAHULUAN}

Pariwisata saat ini telah menjadi salah satu industri andalan utama dalam menghasilkan devisa negara. Kedudukan pariwisata sebagai primadona ekonomi cukup menjanjikan karena dalam situasi kelesuan ekonomi, pariwisata tetap menunjukkan tren peningkatan secara berkelanjutan. Sektor pariwisata di Indonesia juga sedang mengalami peningkatan, baik dalam hal pengembangan destinasi wisata baru, maupun peningkatan jumlah usaha jasa pariwisata dan jumlah kunjungan wisatawan.

Peningkatan sektor pariwisata juga terjadi di Provinsi Jawa Timur, khususnya Kota Malang yang merupakan kota terbesar ke-12 di Indonesia. Kota Malang terletak terletak di tengah Kabupaten Malang dan di dataran tinggi seluas 145,28 km².

Kota Malang mempunyai wisata berupa gedung-gedung kolonial peninggalan Belanda yang sebagian dikonservasi menjadi museum dan sebagian menjadi bangunan dengan fungsi baru dan Kota Malang setiap tahunnya menyelenggarakan festival seni dan budaya bertajuk Malang Tempo Doeloe yang bertempat di sepanjang Jalan Ijen dan beberapa event lainnya. Setiap tahun selalu terjadi peningkatan kunjungan wisatawan di Kota Malang dimana peningkatan kunjungan wisatawan terbesar terjadi di tahun 2016 yaitu sebanyak 1.607 .543 atau dengan persentase sebesar 90,41\% wisatawan dan terjadi penurunan kunjungan wisatawan yang terjadi di tahun 2014 yaitu menurun sebanyak 5.955 wisatawan atau dengan persentase sebesar $-1,69 \%$. Hal tersebut dikarenakan pada awal 2014 pemerintah Kota Malang belum berfokus pada sektor pariwisata. Baru pada akhir 2014, pemerintah kota malang mulai serius menggalakan pembangunan di sektor pariwisata dengan cara membangun destinasi baru dan infrastruktur penunjang pariwisata.

Peningkatan kunjungan wisatawan ke Kota Malang tentunya akan berimbas langsung terhadap sektor industri pendukung pariwisata, salah satunya industri oleh-oleh khas Kota Malang. Oleh-oleh khas Kota Malang sebagian besar berupa makanan. Salah satu toko oleholeh khas Kota Malang yang sedang berkembang adalah Malang Strudel. Hal tersebut dikarenakan Malang Strudel memiliki cabang toko paling banyak diantara toko oleholeh yang lain di Kota Malang. Malang Strudel sendiri awalnya diprakarsai oleh Teuku Wisnu dan Shireen Sungkar yang terinspirasi saat melakukan perjalanan wisata ke Eropa dan sangat menyukai Strudel. Sejak didirikan pada 20 Desember 2014, banyak respon positif tentang rasa lezat Malang Strudel yang memiliki sembilan varian rasa yaitu Apel, Pisang Cokelat, Keju, Strawberry, Nanas, Jeruk, Mixfruit, Red Velvet, dan Green Tea. Malang Strudel memiliki kebijakan, produk Malang Strudel hanya bias dibeli di Kota Malang dengan alasan agar kue ini juga bisa menjadi "khas" kota Malang yang tidak dijual di kota lainnya. Malang Strudel telah membuka enam outlet di Malang yaitu Jl. Ardimulyo No 14 Singosari, Malang, Jl Soekarno Hatta 2 kav 6 Malang, Ruko Istana J1. WR Supratman C3/24, Jl.Diponegoro no.171C Batu, Outlet Bandara Abdurrahman Saleh Malang, dan Jl. Semeru No. 47 Malang.

Sejalan dengan perkembangan sektor pariwisata di Kota Malang, keberadaan Malang Strudel ikut memajukan kearifan lokal, diantaranya dengan memaksimalkan sumber daya buah apel malang dan menjadikan Malang Strudel oleh-oleh khas yang hanya dapat dibeli langsung di Kota Malang. Kemajuan bisnis toko oleh-oleh Malang Strudel tentunya dipengaruhi oleh loyalitas pelanggan, adapun yang dimaksud pelanggan dalam hal ini adalah wisatawan yang berkunjung ke Malang dan membeli Malang Strudel sebagai oleh-oleh.

Loyalitas pelanggan sangat dipengaruhi oleh brand image. Aaker dan Davis (1997) berpendapat bahwa loyalitas terhadap suatu merek sangat dipengaruhi oleh beberapa banyak orang yang sudah loyal pada merek tersebut dikarenakan orang yang sudah loyal bisa mengajak dan menginformasikan kepada orang lain untuk membeli merek tersebut. Pelanggan yang percaya terhadap merek suatu perusahaan kemungkinan besar akan membeli kembali, bahkan menyebarluaskan kabar baik tentang perusahaan bersangkutan.

Citra terhadap merek berhubungan dengan sikap yang berupa keyakinan dan preferensi terhadap suatu merek. Konsumen yang memiliki citra yang positif terhadap suatu merek, akan lebih memungkinkan untuk melakukan pembelian (Setiadi, 2003). Berdasarkan teori diatas, brand image menjadi suatu komponen yang membentuk Toko -oleh malang strudel dimata pelanggan.

Sebagai salah satu toko oleh-oleh yang sedang berkembang dan sebagai ciri khas Kota 
Malang, untuk itu perlu diketahui bagaimana pengaruh pengaruh karakteristik pelanggan toko oleh-oleh Malang Strudel dan brand image terhadap loyalitas pelanggan toko oleh-oleh Malang Strudel.

\section{METODE}

Pengambilan sampel dilakukan di Toko Oleh-Oleh Malang Strudel. Malang Strudel yang merupakan perusahaan bidang kuliner yaitu toko oleh - oleh yang berada di Malang Raya dan toko pertama di Jalan Ardimulyo No 14 Singosari, Malang, Jatim.

Dalam penelitian ini, terdapat tiga variabel yang membentuk brand image dari toko oleholeh Malang Strudel. Tiga variabel tersebut berdasarkan teori yang dikemukakan oleh Keller (1993) yaitu,

1. Kekuatan asosiasi merek

Kekuatan asosiasi merek dalam penelitian ini adalah kekuatan dari merek Malang Strudel yang dibentuk oleh data sensorik otak sehingga konsumen memandang objek stimuli melalui sensasi yang dapat diarasakan oleh kelima indra: mata, telinga, hidung, kulit, dan lidah

2. Keunikan asosiasi merek

Keunikan asosiasi merek dalam penelitian ini adalah membuat kesan unik yang menunjukkan perbedaan tertentu dan signifikan diantara merek-merek lain sebagai nilai saing dan membuat konsumen tertarik untuk memilih Malang Strudel sehingga tujuan dari strategi ini adalah menciptakan asosiasi yang kuat dan unik yang melekat dalam benak konsumen secara mendalam

3. Keuntungan asosiasi merek

Keuntungan asosiasi merek dalam penelitian ini adalah terdapat pada manfaat produk, tersedianya banyak pilihan untuk memenuhi kebutuhan dan keinginan, harga yang ditawarkan bersaing, dan kemudahan mendapatkan produk yang dibutuhkan serta nama perusahaan yang dapat dipercaya

Sedangkan loyalitas pelanggan yang dimaksud dalam penelitian ini adalah pelanggan yang memiliki karakteristik berdasarkan teori yang dikemukakan oleh Griffin (2005) yaitu: melakukan pembelian berulang secara teratur, membeli antarlini produk atau jasa, menunjukan kekebalan terhadap tarikan dari pesaing, mereferensikan kepada orang lain. Dengan empat karakteristik tersebut, peneliti menjadikanya indikator yang dapat menentukan loyalitas pelanggan Malang Strudel.

Teknik pengumpulan data yang digunakan dalam penelitian ini yaitu: obeservasi langsung ke tempat penelitian yakni di toko oleh-oleh malang strudel, wawancara langsung ke pihak toko oleh-oleh malang strudel, kuesioner dengan metode skala likert, dokumentasi dan studi kepustakaan. Adapun penentuan dengan menggunakan model J. Supranto (2006) yaitu mengalikan 5 sampai 10 dengan jumlah pertanyaan (indikator) dalam kuesioner. pengambilan sampel pelanggan dalam penelitian ini, jumlah indikator kuesioner dalam penelitian ini sebanyak 15, maka jumlah responden yang dijadikan sampel sebanyak 160 responden. Hasil tersebut diperoleh dari mengalikan 8 dengan 20 indikator dalam kuesioner., sedangkan pengambilan sampel secara accidental.

\section{HASIL DAN PEMBAHASAN Hasil}

Toko Oleh-oleh Malang Strudel berawal pada saat Teuku Wisnu dan Shireen melakukan perjalanan wisata ke Eropa beberapa tahun silam, keduanya sangat menyukai Strudel hingga terpilihlah kue ini untuk oleh-oleh keluarga dan teman-teman di Indonesia.

Beberapa tahun kemudian, Teuku Wisnu sering datang ke Malang dan tercetus ide untuk membuat Strudel khas Malang agar bisa menjadi oleh-oleh Malang, karena Malang juga terkenal sebagai penghasil apel berkualitas. Strudel yang asli Austria inipun dimodifikasi disesuaikan dengan taste lokal bekerjasama dengan chef profesional. Hingga jadilah beberapa varian Strudel khas Malang yang dijual di gerai pertama Malang Strudel yang dibuka pada tanggal 20

Desember 2014 di Jl Ardimulyo no 14 Singosari, Malang. Sejak 2014, kini Malang Strudel telah memiliki enam outlet yang tersebar di Malang Raya (Kota Malang, Kota Batu, Kabupaten Malang).

\section{Karakteristik Responden}

Berdasarkan hasil pengolahan data, dijelaskan bahwa dari 166 orang responden yang pernah berbelanja di toko oleh-oleh Malang Strudel 69 orang responden (41,60\%) diantaranya adalah laki - laki dan sisanya 97 orang responden adalah perempuan $(58,40 \%)$. Hal ini menunjukkan bahwa sebagian besar responden yang sering berbelanja di toko oleholeh Malang Strudel adalah Perempuan

Dari 166 orang responden yang pernah berbelanja di toko oleh-oleh Malang Strudel dapat diketahui bahwa pelanggan dengan jumlah 
terbesar berasal dari provinsi Jawa Timur dengan jumlah 92 responden $(19,2 \%)$ dari total responden, Jakarta 12 responden $(7,2 \%)$ dari total responden, Jawa Barat $12(7,2 \%)$ dari total responden, dan Madura dengan jumlah 11 responden $(6,6 \%)$ dari total responden. Pelanggan toko oleh-oleh Malang Strudel yang menjadi responden dalam penelitian ini semua berkewarganegaraan Indonesia atau wisatawan domestik. Dari 166 orang responden yang pernah berbelanja di toko oleh-oleh Malang Strudel dapat diketahui bahwa pelanggan dengan jumlah terbesar memiliki profesi sebagai Mahasiswa dengan jumlah 42 responden $(25,3 \%)$, Wiraswasta 40 responden $(24,1 \%)$, Karyawan Swasta 35 responden $(21,1 \%)$ dari total responden, sedangkan pelanggan dengan jumlah profesi terkecil sebagai Pegawai Honorer 1 responden $(0,6 \%)$ dan Ibu Rumah Tangga 4 responden $(2,4 \%)$ dari total responden. Hal ini menunjukkan pelanggan toko oleh-oleh Malang Strudel didominasi oleh Mahasiswa, Wiraswasta, dan Karyawan Swasta.

Berdasarkan hasil pengolahan data, dapat dijelaskan bahwa dari 166 orang responden yang pernah berbelanja di toko oleh-oleh Malang Strudel, jumlah responden tertinggi dalam penelitian ini merupakan responden yang berusia 21-30 tahun sebanyak 92 responden $(55,4 \%)$, sedangkan jumlah responden yang terendah merupakan responden yang berusia 51 tahun keatas sebanyak 3 responden $(1,8 \%)$.

Berdasarkan hasil pengolahan data, dapat dijelaskan bahwa dari 166 orang responden yang pernah berbelanja di toko oleh-oleh Malang Strudel, jumlah responden tertinggi dalam penelitian ini merupakan responden yang memiliki pendidikan terakhir D3/D4/S1/Sederajat sebanyak 101 responden $(60,8 \%)$. Berdasarkan hasil pengolahan data, dapat dijelaskan bahwa dari 166 orang responden yang pernah berbelanja di toko oleholeh Malang Strudel, jumlah responden tertinggi berdasarkan penghasilan per bulan didominasi responden dengan penghasilan $>3-5$ Juta per bulan 60 responden $(36,1 \%)$. Berdasarkan hasil pengolahan data pada, dapat dijelaskan bahwa dari 166 orang responden yang pernah berbelanja di toko oleh-oleh Malang Strudel, dalam penelitian ini berdasarkan jumlah kunjungan didominasi oleh responden yang mengunjungi atau berbelanja di toko oleh-oleh Malang Strudel sebanyak 2x(dua kali) 92 responden $(55,4 \%), 3 x$ (tiga kali) 34 responden
(20,5\%), lebih dari tiga kali 24 responden $(14,5)$, dan satu kali 16 responden $(9,6 \%)$.

\section{Uji Validitas dan Uji Reliabilitas}

Dengan diketahui $d f=164$, maka dapat diperoleh $\mathrm{r}$ tabel dengan signifikansi 0,05 adalah sebesar 0,361. Ketentuanya adalah jika $r$ hitung $>r$ tabel dan $r$ hitung bernilai positif maka instrument dalam penelitian dikatakan valid. Berdasarkan hasil uji validitas diperoleh nilai $r$ hitung untuk masing - masing butir pertanyaan lebih besar dari nilai $r$ tabel (0.361). Dengan demikian untuk 20 butir pernyataan yang diuji dinyatakan valid dan dapat melakukan tahapan berikutnya.

Menurut (Ghozali, 2001), dalam pengambilan keputusan reliabilitas, suatu instrumen dikatakan reliabel jika nilai Cronbach Alpha lebih besar dari 0,6. Dari hasil penelitian diperoleh nilai cronbach alpha lebih besar dari 0,6 . dengan demikian seluruh instrumen yang diuji dalam penelitian ini dapat dinyatakan reliable.

\section{Hasil Analisis Regresi}

Perhitungan statistik analisis regresi linear berganda dilakukan dengan bantuan program komputer SPSS for Windows versi 20. Ringkasan hasil pengolahan data dengan menggunakan SPSS adalah sebagai berikut.

\section{$Y=-4,002+0,300 X 1+0,124 X 2+0,658 \times 3$}

Berdasarkan persamaan di atas, diketahui bahwa nilai konstanta adalah -4,002. Nilai konstanta tersebut menunjukkan bahwa, jika semua variabel bebas bernilai nol, maka loyalitas pelanggan akan bernilai negatif. Dalam hal ini diperlukan usaha oleh perusahaan yang dalam penelitian ini adalah toko oleh-oleh Malang Strudel agar terjadi penambahan nilai tertentu pada kekuatan, keunikan, dan keuntungan dari asosiasi merek sehingga loyalitas pelanggan menjadi positif.

Dari persamaan regresi tersebut dapat diinterprestasikan sebagai berikut :

1. Nilai konstanta sebesar -4,002, setiap terjadi pertambahan satu poin dari variabel bebas, terjadi juga kenaikan nilai sebesar satu angka dalam nilai Loyalitas Pelanggan.

2. X1 (kekuatan asosiasi merek) koefisien regresinya sebesar 0,300 , mempunyai pengaruh positif terhadap Y (loyalitas 
pelanggan). Artinya apabila kekuatan asosiasi merek semakin baik dengan asumsi variabel lain konstan, maka hal tersebut dapat meningkatkan loyalitas pelanggan toko oleh-oleh Malang Strudel sebesar 0,300 .

3. X2 (keunikan asosiasi merek) koefisien regresinya sebesar 0,124 , tidak berpengaruh terhadap Y (loyalitas pelanggan). Artinya ada atau tidak variabel X2 (keunikan asosiasi merek) tidak akan berpengaruh terhadap loyalitas pelanggan.

4. X3 (keuntungan asosiasi merek) koefisien regresinya sebesar 0,658, mempunyai pengaruh yang positif terhadap Y (loyalitas pelanggan). Artinya apabila keuntungan asosiasi merek semakin tinggi dengan asumsi variabel lain konstan, maka hal tersebut dapat meningkatkan loyalitas pelanggan toko oleh-oleh Malang Strudel sebesar 0,658

Dari hasil estimasi regresi terlihat bahwa keuntungan asosiasi merek mempunyai pengaruh paling tinggi terhadap loyalitas pelanggan toko oleh-oleh Malang Strudel, dibandingkan Kekuatan Asosiasi Merek dan Keunikan Asosiasi Merek, yang didasarkan pada nilai koefisien regresi sebesar 0,658 (unstandardized coeficients) dan nilai Beta sebesar 0,450 (standardized coefficients) dengan signifikan sebesar 0,000 atau sig. sebesar $0 \%$.

\section{Hasil Uji t}

Berdasarkan pengujian terhadap koefisien regresi dengan tingkat keyakinan 95\% (significant level 5\%) dan df $=n-4$, maka $t$ tabel yang diperoleh adalah 1,6544, yaitu :

1. Variabel kekuatan asosiasi merek (X1)

Melihat probabilitas signifikansinya (Pvalue) $=0,000$ atau $0 \%$ lebih kecil dari 5\% dan $\mathrm{t}$ hitung $(4,345)>\mathrm{t}$ tabel $(1,6544)$ sehingga dapat disimpulkan Kekuatan Asosiasi Merek berpengaruh signifikan terhadap Loyalitas Pelanggan toko oleh-oleh Malang Strudel.

2. Variabel keunikan asosiasi merek (X2)

Melihat probabilitas signifikansinya (Pvalue) $=0,099$ atau 9,9\% lebih besar dari 5\% dan $\mathrm{t}$ hitung $(1,659)>\mathrm{t}$ tabel $(1,6544)$ sehingga dapat disimpulkan variabel Keunikan Asosiasi Merek tidak berpengaruh signifikan terhadap Loyalitas Pelanggan toko oleh-oleh Malang Strudel.

3. Variabel keuntungan asosiasi merek
Melihat probabilitas signifikansinya (Pvalue) $=0,000$ atau $0 \%$ lebih kecil dari 5\% dan $\mathrm{t}$ hitung $(5,892)>\mathrm{t}$ tabel $(1,6544)$ sehingga dapat disimpulkan variabel keuntungan asosiasi merek berpengaruh signifikan terhadap loyalitas pelanggan toko oleh-oleh Malang Strudel.

\section{Hasil Uji F}

Dengan menggunakan taraf signifikansi 0,05 , diperoleh $\mathrm{F}$ hitung sebesar 66,316 dengan F tabel sebesar 2,66. Dengan demikian F hitung $>\mathrm{F}$ tabel dengan tingkat signifikansi yang diperoleh $0,000<0,05$ sehingga secara bersamasama Kekuatan, Keunikan, Keuntungan berpengaruh secara simultan terhadap Loyalitas Pelanggan toko oleh-oleh Malang Strudel.

\section{Pembahasan}

Secara ringkas, dapat disimpulkan bahwa pelanggan Malang Strudel didominasi oleh kaum perempuan. Pelanggan Malang Strudel didominasi oleh kelompok usia 21-30 tahun, paling banyak berasal dari provinsi Jawa Timur. Persentase terbesar merupakan mahasiswa, dengan penghasilan 3-5 juta per bulan. Sebagian besar pelanggan sudah dua kali melakukan kunjungan ke Malang Strudel.

Hasil perhitungan statistik menunjukan bahwa brand image berpengaruh signifikan terhadap loyalitas pelanggan di toko oleh-oleh Malang Strudel. Diantara ketiga variabel yang mempengaruhi loyalitas pelanggan, variabel keuntungan asosiasi merek merupakan variabel yang berpengaruh paling signifikan dibandingkan dengan dua variabel lainnya.

Secara rinci, dalam variabel kekuatan asosiasi merek, Teuku Wisnu melakukan kontak langsung dengan pelanggan dan profesi Teuku Wisnu sebagai public figure secara langsung memberi dampak terhadap Malang Strudel untuk lebih mudah dikenal dan diingat oleh pelanggan serta meningkatkan loyalitas pelanggan toko oleh-oleh Malang Strudel.

Dalam variabel keunikan asosiasi merek, dapat disimpulkan bahwa produk Malang Strudel bukan oleh-oleh khas Malang dan bukan satu-satunya perusahaan yang menjual kue Strudel. Selain itu, bagi pelanggan, Malang Strudel merupakan salah satu tambahan opsi oleh-oleh khas Malang. Hal tersebut yang menyebabkan variabel kekunikan asosiasi merek berpengaruh tetapi tidak signifikan terhadap loyalitas pelanggan. 
Dalam variabel keuntungan asosiasi merek, letak enam outlet Malang Strudel yang terletak di tempat-tempat strategis seperti outlet di Jl. Semeru No. 47 Malang yang lokasinya berdekatan dengan Malang Car Free Day (CFD) yang diadakan setiap hari minggu, outlet di J1 Soekarno Hatta Kav. D 408 yang terletak daerah wisata kuliner Kota Malang, dan outlet terbesar di Jl. Ardimulyo No 14 Singosari, Malang yang terletak di jalan antar kota sangat memudahkan pelanggan untuk menjangkau toko oleh-oleh Malang Strudel.

\section{SIMPULAN DAN SARAN Simpulan}

Berdasarkan penelitian tentang pengaruh brand image terhadap loyalitas pelanggan di Toko Oleh-oleh Malang Strudel, maka diperoleh kesimpulan Secara simultan, variabel kekuatan asosiasi merek(X1), keunikan asosiasi $\operatorname{merek}(\mathrm{X} 2)$, keuntungan asosiasi merek(X3) yang membentuk brand image, berpengaruh terhadap loyalitas pelanggan, keuntungan asosiasi merek merupakan variabel yang paling dominan pengaruhnya terhadap loyalitas pelanggan di toko oleh-oleh Malang Strudel. Adapun secara parsial variabel kekuatan asosiasi merek(X1) dan keuntungan asosiasi merek(X3) berpengaruh secara signifikan, sedangkan variabel keunikan asosiasi merek(X2) berpengaruh tetapi tidak signifikan.

Berdasarkan hasil penelitian diperoleh 55\% loyalitas pelanggan dapat dijelaskan oleh variabel Kekuatan asosiasi merek, Keunikan asosiasi merek, Keuntungan asosiasi, sedangkan sisanya yaitu $45 \%$ loyalitas pelanggan dipengaruhi oleh variabel-variabel lainnya yang tidak diteliti dalam penelitian ini.

Kekuatan asosiasi merek(X1) dan keuntungan asosiasi merek(X3) berpengaruh secara signifikan disebabkan oleh faktor letak outlet Malang Strudel yang strategis serta faktor dari Teuku Wisnu yang menjadi public figure sehingga memudahkan produk Malang Strudel dikenal.

\section{Saran}

Berdasarkan hasil penelitian mengenai pengaruh brand image terhadap loyalitas pelanggan di Toko Oleh-oleh Malang Strudel, saran yang dapat penulis berikan adalah sebagai berikut:

1. Toko oleh-oleh Malang Strudel perlu meningkatkan keunikan dari produk kue Strudel sehingga dapat mewakili apel malang seperti membuat variasi dari rasa apel sehingga dapat bersaing dengan toko oleh-oleh yang lain baik yang memiliki produk sama yaitu kue Strudel atau produk olahan apel lainya.

2. Toko oleh-oleh Malang Strudel perlu lebih menonjolkan bahwa Toko oleh-oleh Malang Strudel merupakan perusahaan pertama yang menjual kue Strudel di kota Malang yang ditulis melalui semboyan atau dengan membuat jargon-jargon khusus.

3. Perlu dilakukan penelitian lebih lanjut terhadap faktor-faktor selain kekuatan asosiasi merek, keunikan asosiasi merek, keuntungan asosiasi merek yang berpengaruh terhadap loyalitas pelanggan toko oleh-oleh Malang Strudel. Hal ini dikarenakan, dalam penelitian ini keempat variabel tersebut hanya mampu menjelaskan 54,2 persen variasi loyalitas pelanggan. Penelitian ini belum memasukkan variabel atas aspek lain yang mungkin dapat mempengaruhi dan menyempurnakan hasil penelitian ini.

4. Untuk penelitian yang akan datang disarankan untuk meneliti toko oleh-oleh lainnya baik yang dimiliki oleh public figure atau pengusaha toko oleh-oleh biasa yang sedang menjadi trend dewasa ini. Dengan mengambil contoh produk atau merek lain maka permasalahan yang dialami dalam brand image yang dalam penelitian ini dibentuk oleh kekuatan asosiasi merek, keunikan asosiasi merek, keuntungan asosiasi merek terhadap loyalitas pelanggan tersebut tentu juga berbeda, sehingga variabel yang mempengaruhi loyalitas pelanggan juga berbeda. Hal ini dapat dijadikan pembanding sekaligus melengkapi penelitian ini. 


\section{Kepustakaan}

Anonim. $\quad<$ https://malangkota.go.id/wpcontent/uploads/2017/06/Kota-MalangDalam-Angka-2013.pdf> $<$ https://malangkota.go.id/wpcontent/uploads/2017/06/Kota-MalangDalam-Angka-2015.pdf> $<$ https://malangkota.go.id/wpcontent/uploads/2017/06/Kota-MalangDalam-Angka-2016.pdf>

Aaker, D. A. 1991, Managing Brand Eqiuty: Capitalizing on The Value Of a Brand Name. New York: The Free Press.

Griffin , Jill. 2005. Customer Loyalty, Menumbuhkan dan Mempertahankan Kesetiaan Pelanggan. Jakarta: Erlangga,

Keller, K.L. 1993. Conceptualizing, Measuring and Managing Customer-based brand equity. Journal of Marketing, 57, pp. 122

Pemerintah Kota Malang, Tingkat Kunjungan

Wisatawan, diunduh pada tanggal 13

Februari 2018 pukul 21.59 WITA

$<$ https://malangkota.go.id/wpcontent/uploads/2015/04/Malang-DalamAngka 2012.pdf>

Pemerintah Kota Malang, Tingkat Kunjungan Wisatawan. diunduh pada tanggal 13 Februari 2018 pukul 21.59 WITA

Pemerintah Kota Malang, Tingkat Kunjungan Wisatawan. diunduh pada tanggal 13 Februari 2018 pukul 21.59 WITA $<$ https://malangkota.go.id/wpcontent/uploads/2017/06/Kota-MalangDalam-Angka-2014.pdf>

Pemerintah Kota Malang, Tingkat Kunjungan Wisatawan. diunduh pada tanggal 13 Februari 2018 pukul 21.59 WITA)

Pemerintah Kota Malang, Tingkat Kunjungan Wisatawan. diunduh pada tanggal 13 Februari 2018 pukul 21.59 WITA

Setiadi, Nugroho, SE., MM. 2003. Perilaku Konsumen Konsep dan Implikasi untuk Strategi dan Penelitian Pemasaran. Jakarta: Kencana.

Supranto, Johanes. 2006. Pengukuran Tingkat Kepuasan Pelanggan Untuk Menaikan Pangsa Pasar.Jakarta : PT.Rineka Cipta 